\title{
Maxillary Impacted Conines: A Clinical Review
}

\author{
Dr Rajiv Yadav,' Dr Basanta K. Shrestha \\ 'Lecturer, ${ }^{2}$ Asso Prof, Department of Orthodontics, \\ Institute of Medicine, Tribhuvan University Teaching Hospital, Kathmandu, Nepal
}

Correspondence: drbkshrestha@gmail.com

\section{INTRODUCTION}

Impacted teeth are those with a delayed eruption time or that are not expected to erupt completely based on clinical and radiographic assessment., ${ }^{1,2}$ Palatal displacement of the maxillary canines is defined as the developmental dislocation to a palatal site often resulting in tooth impaction requiring surgical and orthodontic treatments. ${ }^{3,4}$

Impacted permanent maxillary canine occur in 1-2\% of the population. The Occurrence of impacted permanent maxillary canines are; $85 \%$ palatal and $15 \%$ labial. ${ }^{1,2,5,6}$ The prevalence of palatally displaced canines (PDC) fluctuates between 0.8-5.2\%.2,3,15,12,16,17 Palatally erupting or impacted maxillary canines occur twice often in females than males, and are five times more common in Caucasians than Asians.3,18,19 Of all patients with maxillary impacted canines, $8 \%$ have bilateral impactions.

\section{Etiology and Developmental Considerations}

The exact etiology of palatally impacted maxillary canine is unknown; however, two common theories may explain the phenomenon: the guidance theory and the genetic theory. Guidance theory of palatal canine displacement proposes that the congenitally missing lateral incisors, supernumerary teeth, odontomas, transposition of teeth and other mechanical determinants interfere with the path of eruption of the Canine. 1,2,8,15,21 Maxillary canines develop high in the maxilla, are the last teeth to develop, travel longest and most complicated eruption path among all teeth. Between the age 5 to 15 years, normal eruption path of the maxillary canine is altered causing impaction. 3,19,12,20 The second theory focuses on genetic cause stating that the palatally impacted maxillary canines often accompany other dental abnormalities like tooth size, shape, number, structure. Studies show that upto $47.7 \%$ of patients with palatally impacted canines also possess small, pegshaped or missing lateral incisors. Palatally impacted maxillary canines are also associated with hypoplastic enamel, infra-occluded primary molars and aplastic second bicuspids. ${ }^{1,21}$

If orthodontic treatment is not provided for impacted canine, complications such as root resorption of the neighbouring lateral incisor and first premolar, and development of cyst may occur. 3,4,12,14,18,22,24,25,26

\section{Diagnosis}

Accurate localization of the impacted tooth plays a crucial role in determining the feasibility, proper access for the surgical approach and direction for application of orthodontic force. Ideally, patients should be examined by the age of 8 to 9 years to determine whether the canine is displaced from a normal position in the alveolus and assess the potential for impaction. ${ }^{1,27}$

\section{Clinical evaluation}

Visual Inspection of the patient include lack of a canine bulge in the buccal sulcus by the age of 10 years, ${ }^{1,28}$ 
over retained primary cuspids, ${ }^{1,29}$ no significant mobility of deciduous canine at age of 13 years, ${ }^{1,29}$ an exaggerated distally tipped incisor, ${ }^{1,28}$ retroclined and rotated lateral incisors, ${ }^{1,28}$ and malpositioned central incisor crown. ${ }^{1,30}$

Palpation of canine bulge shows an obvious palpable bilateral asymmetry in patients older than 10 years. 1,31,32 Radiographic evaluation includes panoramic view (OPG), lateral cephalogram, IOPA x-rays with parallax technique (horizontal/vertical) and occlusal view. Specialized views include CT and CBCT (Figure 1,2,3,4).

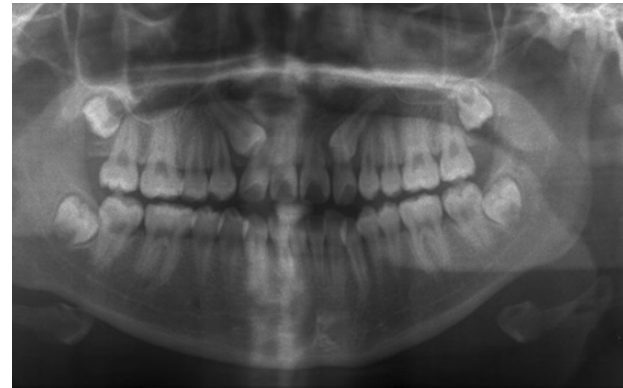

Figure 1: Panoramic x-ray

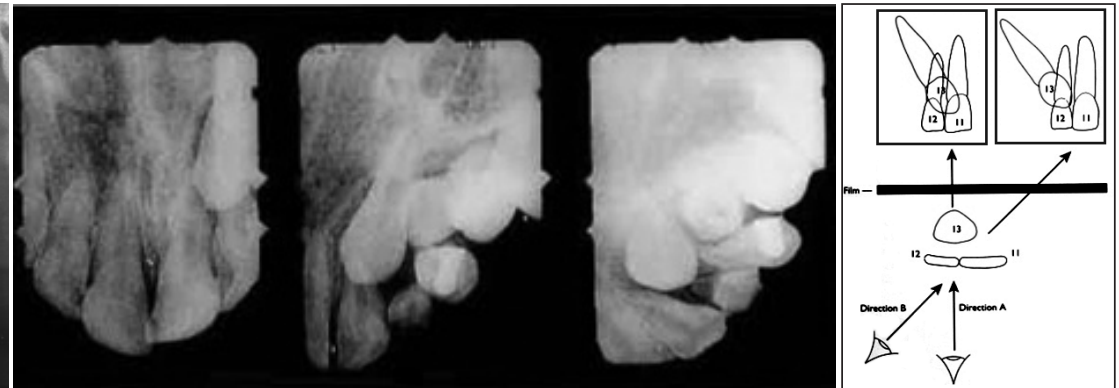

Figure 2: Periapical Radiograph with Parallax method (Cone shift)

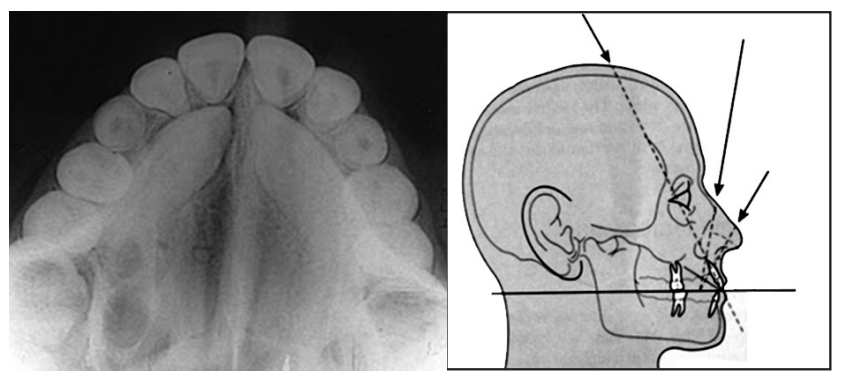

Figure 3: Occlusal view with Projection angle

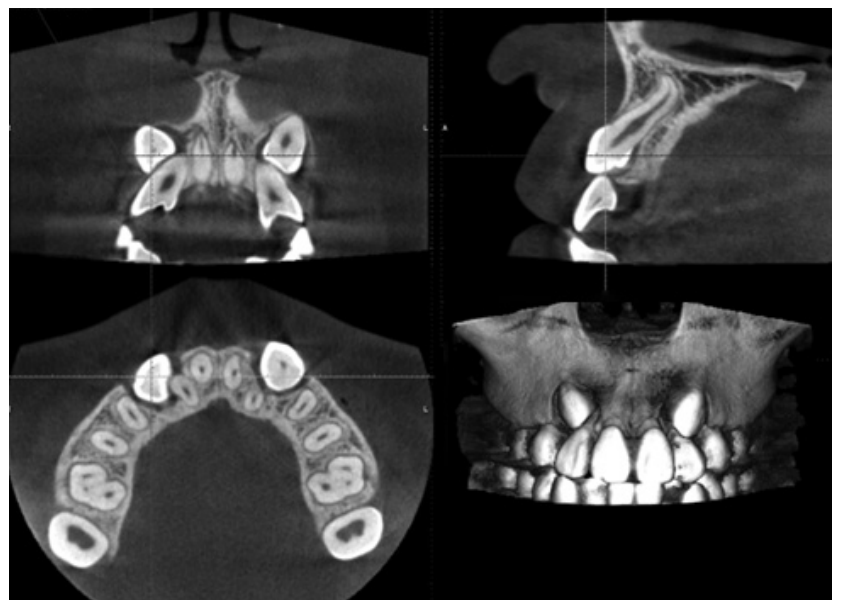

Figure 4: 3D CBCT view
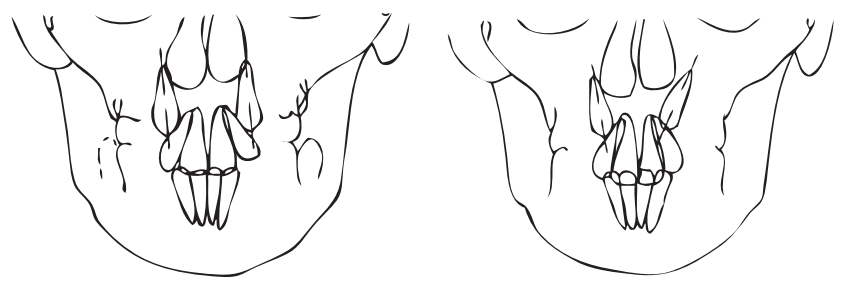

Figure 5: Normal \& mesial orientation of impacted canine

\section{Management of Impacted Canine}

\section{Preventive \& interceptive measures}

The procedure of reducing the occurrence of impacted palatally displaced canines by extracting the primary canine was reported by Buchner in 1936. Selective extraction of deciduous canines as early as 8 to 9 years of age has been suggested by Williams as an interceptive approach to canine impaction in Class I uncrowded cases. Finally, the prospective study by Ericson and Kurol in 19883,13 analyzed the effect of extraction of primary canine on PDC in terms of rate and time of 'spontaneous' eruption. They suggested that the removal of primary canine before the age of 11 years will normalize the position of permanent canines in $91 \%$ cases, if the canine crown is distal to the midline of the lateral incisor. On the other hand, the success rate is $64 \%$ if the canine crown is mesial to the midline of the lateral incisors (Figure 5). In a 2-year longitudinal study, Power and Short 3,29 reported the achievement of normal eruptive position of PDC in 62 per cent of subjects following the extraction of the primary canines. More recent study by Leonardi et al. ${ }^{3,32}$ failed to find significant effectiveness of primary canine extraction for the treatment of PDC. Baccetti et al did a randomized clinical trial in 2008 and concluded that the extraction of primary canine is an effective way to normalize the eruption of maxillary canine by two times the possibility than in untreated controls. The use of cervical-pull headgear in addition to the extraction of the primary canine is able to significantly increase the rate of successful eruption of the permanent canine by up to three times more than in the untreated controls. 


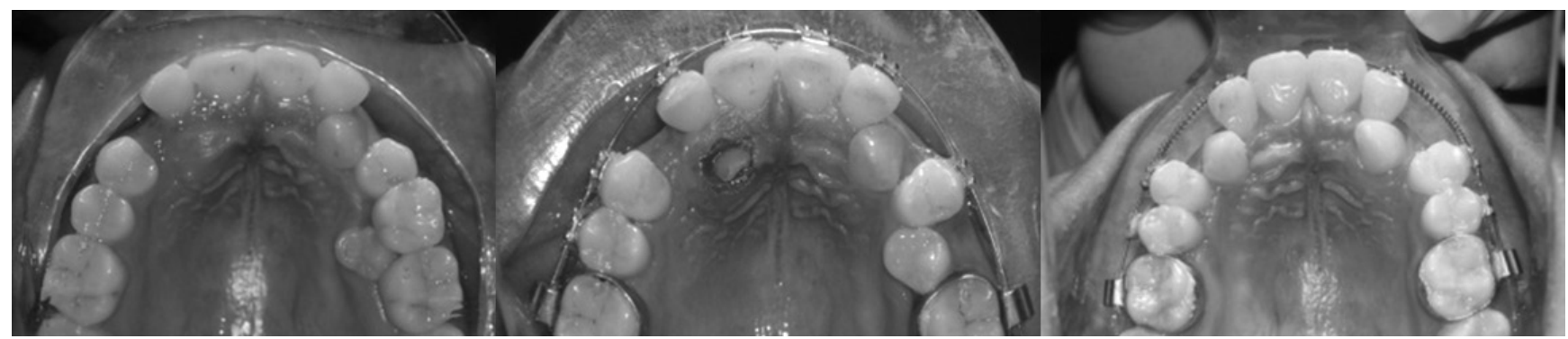

Figure 6: Surgical exposure allowing natural eruption

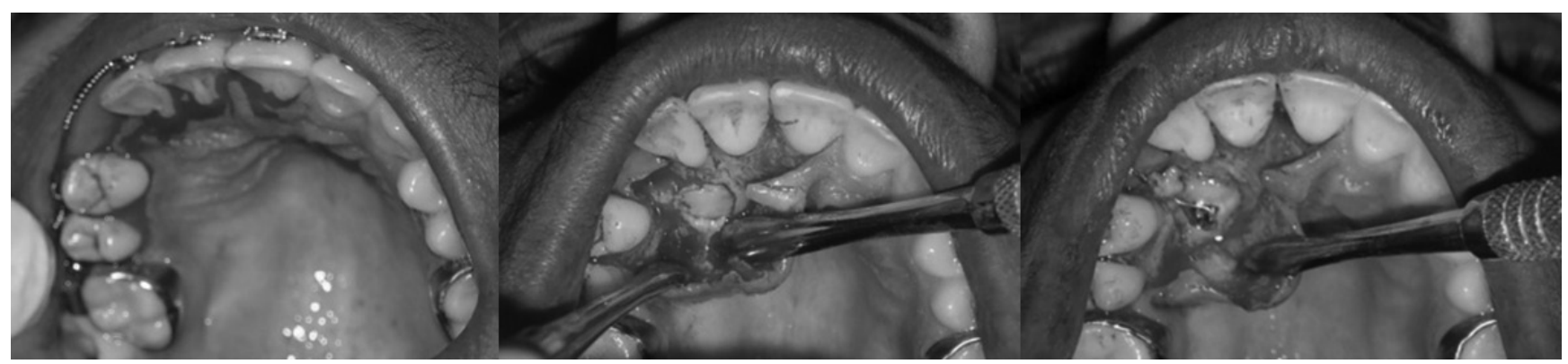

Figure 7: Auxillary attached to impacted tooth during surgical exposure

Hence it can be concluded that the extraction of deciduous canine before the age of 11 years is still an accepted interceptive approach to prevent canine impaction.

\section{Alternative Treatment modalities:}

1. Auto transplantation of the canine.

2. Extraction of the impacted canine and movement of a first premolar in its position.

3. Extraction of the canine and posterior segmental osteotomy to move the buccal segment mesially to close the residual space.

4. Trans-alveolar transplantation of maxillary canines (Both are tedious surgical procedures).

5. Prosthetic replacement of the canine (not amenable for juvenile patients).

6. Surgical exposure of the canine and orthodontic treatment to bring the tooth into the line of occlusion (Obviously the most desirable approach).

\section{Management of palatally impacted canine}

There are numerous surgical methods for exposing the impacted canine and bringing it to the line of occlusion. The most commonly used methods are:

1. Surgical exposure, allowing natural eruption to occur (Figure 6)

2. Surgical exposure with the placement of an auxiliary a. Lewis' two-step approach: First the canine is surgically uncovered and the area is packed with a surgical. After wound healing within 3 to 8 weeks, the pack is removed, and an auxiliary is attached on the exposed impacted tooth.

b. One-step approach: The auxiliary is attached on the exposed tooth during the time of surgical exposure. The tissues over the attachment should be excised, and a periodontal pack should be placed (Figure 7).

\section{Management of labially impacted canine}

Management of labially impacted canines involves a stepwise procedure, as follows (Figure 8):
a. Surgical exposure
b. Placement of orthodontic attachment
c. Traction force application

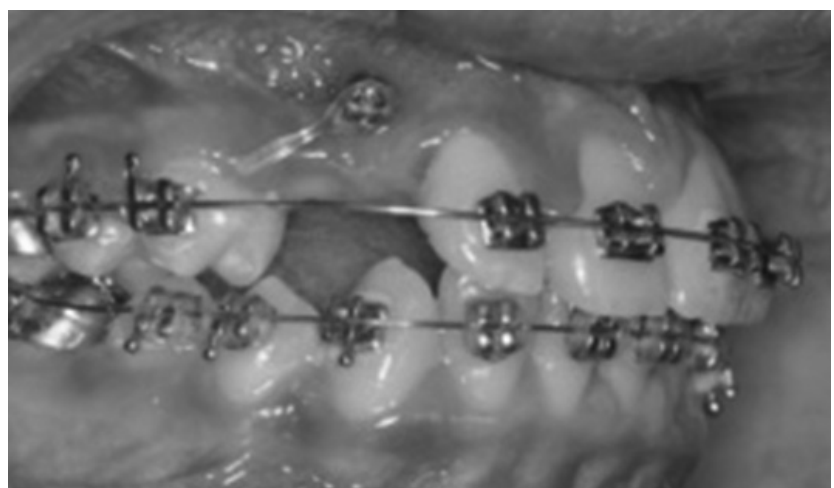

Figure 8: Retraction of labially impacted canine 


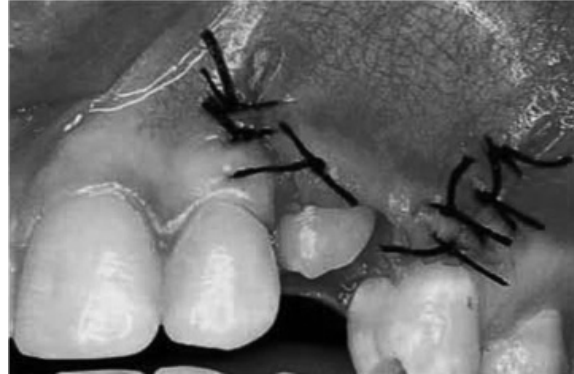

Figure 9: Apically positioned flap

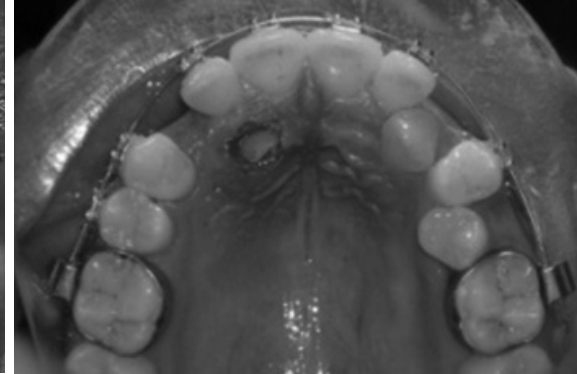

Figure 10: Excisional gingivectomy

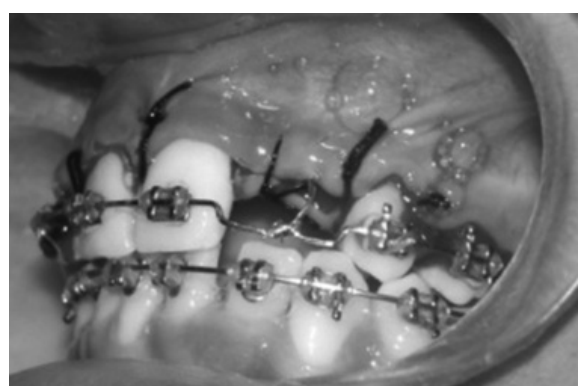

Figure 11: Closed eruption technique

\section{Surgical exposure}

It is recommended that the surgical procedure designed to expose impacted canine through alveolar mucosa should simultaneously provide a band of attached gingival to the exposed tooth. Otherwise, improper soft-tissue management may lead to mucogingival recession and loss of alveolar bone. Before a labially impacted canine is exposed, consideration should be given to create the sufficient space to allow the canine to be moved in the area.

The most common surgical methods are:

a. Apically positioned flap (Figure 9)

b. Excisional gingivectomy (Figure 10)

c. Closed eruption technique (Figure 11)

Among the above mentioned methods, closed eruption technique is the best method of uncovering labially impacted tooth. It involves elevating a flap, placing an attachment on the impacted tooth and returning the flap to its original location. If the tooth is displaced near the nasal spine; pedicle flap is reflected, orthodontic attachment is placed and the flap is returned to its original position for complete closure. The orthodontic traction force is applied one week after creating a normal direction of tooth eruption.

\section{Methods of orthodontic attachment}

1. Polycarbonate or gold crowns cemented onto the exposed crown

2. Wire lasso (Figure 12)

3. Drilling hole at canine tip and passing ligature through the hole then traction force is applied.

4. Orthodontic attachment of bondable mesh, bracket or lingual button with ligature chain or to the bonded attachment (Figure 13).

5. Multiple eyelet chain.

6. Magnets in attractive mode.

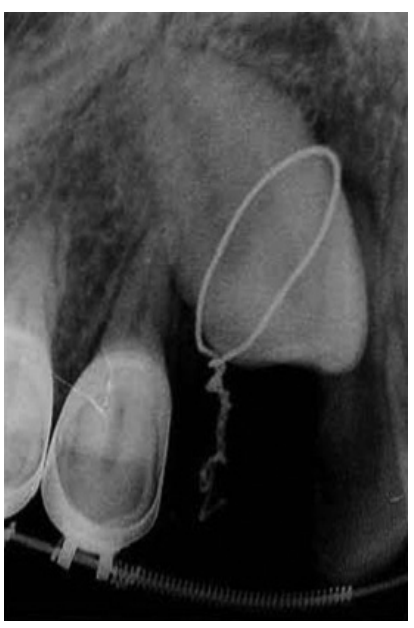

Figure 12: Wire lasso

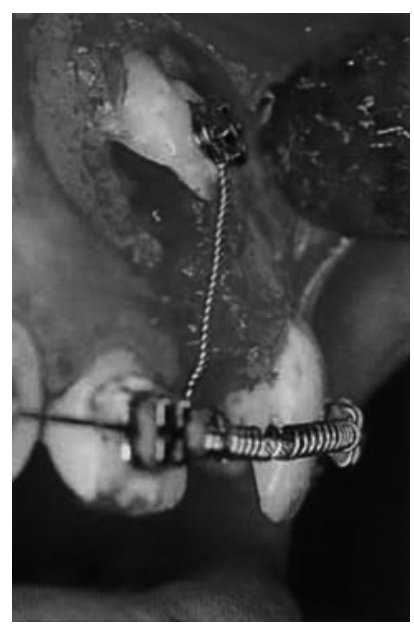

Figure 13: Bondable bracket with ligature

\section{Methods of applying traction}

Following considerations are recommended:

1. Use of light force to move impacted tooth; not more than 2 ounces (60 grams)

2. Availability or creation of sufficient space in the arch for impacted tooth

3. Maintenance of the space either by continuous tying of the teeth or placement of a passive open coiled spring on the arch wire.

4. Provision by the arch wire of sufficient stiffness (e.g. $0.018 \times 0.022)$ to resist deformation by the forces applied to it as the canine is extruded.

\section{Extrusion of palatally impacted canines}

1. Kobayashi Hook

2. Split rectangular extra oral hook

3. Specially bent 0.018" wire.

4. Multiple eyelet chain

5. Ballista spring system for impacted teeth 

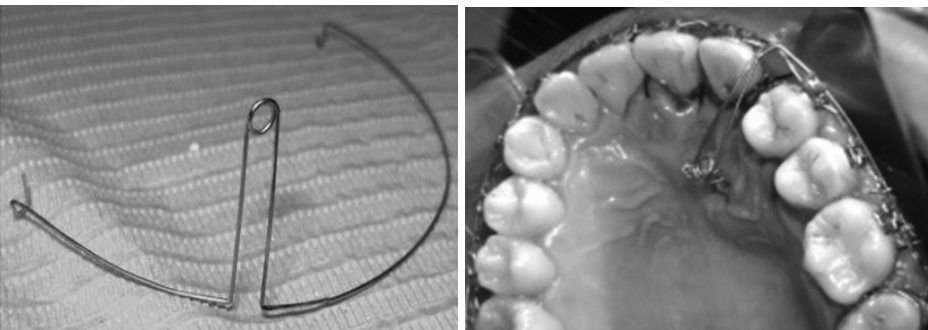

Figure 14: Ballista spring

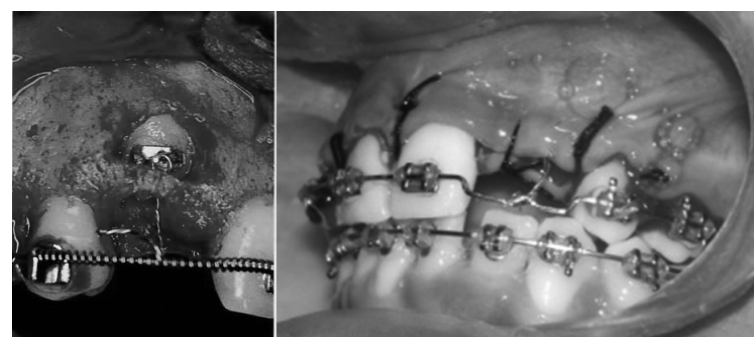

Figure 15: Tunnel traction of intraosseous impaction
6. Tunnel-traction of infraosseous impacted maxillairy canines.

7. Rare earth magnets

8. Two arch wire technique for alignment of impacted teeth

\section{When to extract an impacted canine?}

1. If it is ankylosed and cannot be transplanted.

2. If it is undergoing external or internal root resorption.

3. If the root is severely dilacerated.

4. If the impaction is severe on central and lateral incisors and orthodontic movement will jeopardize these teeth.

5. If the occlusion is acceptable with the first premolar in position of canine with an excellent occlusion and well aligned teeth.

6. If there are pathological lesions (e.g. cyst, infection).

7. If the patient does not desire orthodontic treatment.

\section{Retention}

Backer et al evaluated the post-treatment results of impacted canines. They observed an increased incidence of rotations and spacings on the impacted side in $17.4 \%$ of the cases, whereas on the control side the incidence was only $8.7 \%$. The control side had ideal alignment twice as compared to the impacted side.

To minimize or prevent rotational relapse, circumferential supracrestal fiberotomy or a bonded fixed retainer is required completion of the treatment and sometimes even before the appliances are removed. Clark suggested that after the alignment of palatally impacted canines, lingual drift can be prevented by removal of a half-moon shaped wedge of tissue from the lingual aspect of the canine.

\section{CONCLUSION}

The occurrence of maxillary canine impaction is considerable and the frequency increases with other genetically associated dental anomalies. The practitioner should be aware of early recognition and interceptive measures and most importantly, if the signs of ectopic eruption are detected early, every effort should be made to prevent impaction and its consequences.

Recent management protocol involves judicial extraction of the primary canine and radiographic follow-up for 12 months to monitor eruption. The need for complex orthodontic treatment and surgical intervention may be avoided if the deciduous canines are extracted appropriately. Early intervention can prevent the patient time, expense, complex treatment and injury to otherwise healthy teeth. In specific cases, extraction of the primary canines may prevent impaction of the permanent maxillary canines and additional sequelae. The management of severely impacted canine is often a complex undertaking and requires the multi-disciplinary expertise.

\section{OJN}




\section{REFERENCES}

1. Grace Richardson, Kathy A. Russell. A review of impacted permanent maxillary canine: Diagnosis and prevention. J Can Dent Assoc 2000; 66:497-501.

2. Thilander B, Jakobsson SO. Local factors in impaction of maxillary canines. Acta Odontol Scand 1968; 26:145-68.

3. Ali Alqerban, Reinhilde Jacobs, Steffen Fieuws, Guy Willems. Comparison of two cone beam computed tomographic systems versus panoramic imaging for localization of impacted maxillary canines and detection of root resorption. Eur J Orthod 2011:33:93- 102.

4. Peck S, Peck L, Kataja M. Site-specificity of tooth maxillary agenesis in subjects with canine malpositions. Angle Orthod.1996; 66:473-6.

5. Tiziano Baccetti, Maria Leonardi and Pamela Armi A randomized clinical study of two interceptive approaches to palatally displaced canine. Eur J Orthod 2008; 30: 381-5.

6. Shah RM, Boyd MA, Vakil TF. Studies of permanent tooth anomalies in 7886 Canadian individuals. J Can Dent Assoc 1978;44:262-4.

7. Rayne J. The unerupted maxillary canine. Dent Pract Dent Rec 1969;19:194-204.

8. Bass TB. Observations on the misplaced upper canine tooth. Dent Pract Dent Rec 1967; 8:25-33.

9. Hitchin AD. The impacted maxillary canine. Br Dent J 1956; 100:1-14.

10. Dachi SF, Howell FV. A survey of 3874 routine full mouth radiographs. Oral Surg Oral Med Oral Pathol 1961;14:1165-9.

11. Moss J P 1972 The unerupted canine. Dental Practitioner 22:241-248.

12. Ericson S, Kurol J. Radiographic examination of ectopically erupting maxillary canines. Am J Orthod Dentofac Orthop 1987: 91:483-92

13. Ericson S , Kurol J. Early treatment of palatally erupting maxillary canines by extraction of primary canines. Eur J Orthod; 10:283-95

14. Ericson S, Kurol J. Resorption of incisors after ectopic eruption of maxillary canines. A CT study. Angle Orthod 2000; 70:415-23.

15. Brin I, Becker A, Shalhav M. Position of the permanent canine in relation to anomalous or missing lateral incisors: a population study. Eur J Orthod 1986; 8:12-6.

16. Baccetti T. A controlled study of associated dental anomalies. Angle Orthod 1998; 68:267-74.

17. Chu F C, Li TK, Lui VK, Newsome PR, Chow RL, Cheung LK. Prevalence of impacted teeth and associated pathologies-a radiographic study of the Hong Kong Chinese population. Hong Kong Medical Journal 2000; 9:158-63.

18. Bishara SE. Impacted maxillary canines: A review. Am J Orthod Dentofacial Orthop 1992; 101:159-71.

19. Peck S, Peck L, Kataja M. The palatally displaced canine as a dental anomaly of genetic origin. Angle Orthod 1994; 64:249-56.

20. Bjerklin K, Ericson S. How a computerized tomography examination changed the treatment plans of 80 children with retained and ectopically positioned maxillary canines. Angle Orthod 2006;76: 43-51.

21. Baccetti T. A controlled study of associated dental anomalies. Angle Orthod 1998; 68:267-74.

22. Rimes RJ, Mitchell CNT, Willmot DR. Maxillary incisor root resorption in relation to the ectopic canine: a review of 26 patients. Eur J Orthod 1997;19:79-84.

23. McSherry PF. The ectopic maxillary canine: a review. British J Orthod 1998; 25:209-16.

24. Postlethwaite KM. Resorption of premolar roots by ectopic canines. British Dental Journal 1989; 167:397-8.

25. Cooke ME, nute SJ. Maxillary premolar resorption by canines: three case reports. International Journal of Paediatric Dentistry 2005;15:210-212.

26. Walker L, Enciso R, Mah J. Three-dimensional localization of maxillary canines with cone-beam computed tomography. Am J Orthod Dentofac Orthop 2005; 128:418-423.

27. Shapira Y, Kuftinec MN. Early diagnosis and interception of potential maxillary canine impaction. JADA 1998; 129:1450-4.

28. Power SM, Short MB. An investigation into the response of palatally displaced canines to the removal of deciduous canines and an assessment of factors contributing to favourable eruption. Br J Orthod 1993; 20:217-23.

29. Jacobs SG. Reducing the incidences of palatally impacted maxillary canines by extraction of deciduous canines: a useful preventive/interceptive orthodontic procedure. Case reports. Aust Dent J 1992; 37:6-11.

30. Ericson S, Kurol J. Longitudinal study and analysis of clinical supervision of maxillary canine eruption. Community Dent Oral Epidemiol 1986; 14:172-6.

31. Jacoby H. The etiology of maxillary canine impactions. Am J Orthod 1983; 84:125-32.

32. Leonardi $M$, Armi $P$, Franchi $L$, Baccetti $T$. Two interceptive approaches to palatally displaced canines: a prospective longitudinal study. Angle Orthod 2004;75:581-6. 